\title{
IMPLEMENTASI NILAI-NILAI PANCASILA DALAM MENINGKATKAN SUMBER DAYA MANUSIA INDONESIA
}

\author{
Amanda Ramadhan Firdaus \& Dinie Anggraeni Dewi \\ Universitas Pendidikan Indonesia \\ amanda12@upi.edu
}

\begin{abstract}
Abstrak
Penelitian ini dilakukan untuk mengetahui upaya dalam meningkatkan sumber daya manusia Indonesia melalui aspek pendidikan dengan mengimplementasikan nilai-nilai pancasila. Metode penelitian ini dilakukan menggunakan pendekatan kualitatif yang bersifat analisis deskriptif, dengan metode kepustakaan/library research yang bersumber dari jurnal dan artikel. Hasil dari penelitian ini didapat bahwa pendidikan merupakan aspek yang sangat berpengaruh terhadap sumber daya manusia. Oleh karena itu, kualitas pendidikan di Indonesia harus ditingkatkan. Sistem Pendidikan dalam metode belajar mengajar harus didasarkan dengan nilai-nilai Pancasila agar teratur dan tearah prosesnya sehingga mewujudkan tujuan Pendidikan yang sebenarnya dan membentuk moral anak bangsa yang memiliki karakter berdasarkan nilai-nilai Pancasila.
\end{abstract}

Kata kunci: Nilai-Nilai Pancasila, Sumber Daya Manusia, Pendidikan.

\begin{abstract}
This research was conducted to determine the efforts to improve Indonesia's human resources through educational aspects by implementing Pancasila values. This research method is carried out using a qualitative approach that is descriptive analysis, with the method of library research which is sourced from journals and articles. The results of this study indicate that education is an aspect that is very influential on human resources. Therefore, the quality of education in Indonesia must be improved. The education system in the teaching and learning method must be based on the values of Pancasila so that the process is regular and unorganized so as to realize the true goals of education and form the moral of the nation's children who have character based on the values of Pancasila.
\end{abstract}

Keywords: Pancasila Values, Human Resources, Education.

\section{PENDAHULUAN}

Pancasila merupakan kumpulan lima nilai unidimensional yang dijadikan acuan tingkah laku bangsa Indonesia (Kariyadi, 2017). Kelima nilai yang terkandung dalam Pancasila adalah ketuhanan pada sila pertama, kemanusiaan pada sila kedua, patriotisme pada sila ketiga, demokrasi pada sila keempat, dan keadilan sosial pada sila kelima. Sebagai ideologi nasional, nilainilai dasar Pancasila menjadi cita-cita masyarakat Indonesia yang sekaligus merupakan karakter bangsa yang hendak dibangun dari nilai-nilai yang terkandung dalam Pancasila (Nurgiansah, 2020).

Karakter, identitas atau jati diri sebuah bangsa itu tercipta dari hasil pembudayaan melalui pendidikan, karenanya karakter bukanlah sesuatu yang telah ada dengan sendirinya melainkan perlunya peran pendidikan untuk membentuk karakter yang berlandaskan kebaikan. Pancasila mendasari dan menjiwai semua proses penyelenggaraan negara dalam berbagai bidang serta menjadi rujukan bagi seluruh rakyat Indonesia dalam bersikap dan bertindak dalam kehidupannya sehari-hari. Pancasila sebagai penunjuk arah dari setiap sikap dan tindakan yang dilakukan oleh setiap warga negara Indonesia dalam kehidupan bermasyarakat, berbangsa, dan bernegara.

Terdapat tiga tataran nilai dalam ideologi Pancasila yaitu pertama nilai dasar merupakan prinsip, yang bersifat amat abstrak, bersifat amat umum, tidak terikat oleh waktu dan tempat, dengan kandungan kebenaran yang bagaikan aksioma. Dari 
segi kandungan nilainya, maka nilai dasar berkenaan dengan eksistensi sesuatu, yang mencakup cita-cita, tujuan, tatanan dasar dan ciri khasnya. Kedua, nilai instrumental yaitu suatu nilai yang bersifat kontekstual. Nilai instrumental merupakan penjabaran dari nilai dasar tersebut. Nilai instrumental merupakan kebijaksanaan, strategi, organisasi, sistem, rencana, program, bahkan juga proyek-proyek yang menindaklanjuti nilai dasar tersebut. Lembaga negara yang berwenang menyusun nilai instrumental ini adalah MPR, Presiden, dan DPR. Ketiga, Nilai praksis, yaitu nilai yang terkandung dalam kenyataan sehari-hari, berupa cara bagaimana rakyat melaksanakan (mengaktualisasikan) nilai Pancasila.

\section{METODE PENELITIAN}

Penelitian ini dilakukan dengan pendekatan kualitatif. Dalam menganalisis data dilakukan menggunakan analisis deskriptif dengan metode kepustakaan/library research yaitu pengumpulan data penelitian mengenai teori-teori yang berkaitan dengan masalah yang dibahas di dalam penelitian ini, sumber data yang diperoleh sebagai referensi untuk menunjang penelitian ini bersumber dari beberapa artikel dan jurnal yang relevan dan selaras dengan penelitian terkait Pengimplementasian nilai-nilai Pancasila. Sedangkan, instrumen penelitian ini adalah peneliti itu sendiri karena peneliti sendiri yang menentukan dan menetapkan topik pembahasan pada penelitian, mencari dan menganalisis teori yang berkaitan dengan penelitian sampai didapatkan sebuah kesimpulannya.

\section{HASIL PENELITIAN DAN PEMBAHASAN Hasil Penelitian}

Sumber Daya Manusia (SDM) merupakan sumber suatu keorganisasian baik dalam perusahaan besar yang memiliki fungsi besar sebagai alat sehingga harus dilatih dan dikembangkan kemampuannya. Sumber Daya Manusia (SDM) merupakan faktor kunci dalam persaingan global untuk menciptakan SDM yang memiliki ketrampilan serta berdaya saing yang tinggi dalam persaingan global (Putri, 2020). Ruang sumber daya manusia meliputi jumlah komposisi, karakteristik (kualitas) dan persebaran penduduk. Dimensi ini memiliki kaitan satu dengan yang lainnya yang memiliki kaitan antara kuantitas dan kualitas berupa komposisi, dan persebaran yang sangat penting. Untuk menciptakan sumber daya manusia di indonesia yang memiliki kualitas pendidikan mempunyai modal utama dalam pembangunan masyarakat indonesia.

Kekayaan dan keanekaragaman yang dimiliki oleh warga negara indonesia memiliki daya guna yang telah dikelola dan diatur oleh sumber daya manusia yang terdidik dan ahli dalam bidangnya melalui pengajaran. Oleh karenanya, perlu dibangun sistem pendidikan yang diletakkan di atas fondasi kebhinekaan. Dengan fondasi kebhinekaan dan pancasila, proses belajar-mengajar akan berisi karakter kejujuran, kebersamaan, toleransi kesopanandan peduli kepada orang lain. Sikap jujur, menghargai sesama, dan kepedulian yang dibangun melalui dunia pendidikan akan menjadi karakter dalam kehidupan sehari-hari masyarakat Indonesia.

Pendidikan karakter menurut Thomas Lickona adalah pendidikan untuk membentuk kepribadian seseorang melalui pendidikan budi pekerti, yang hasilnya terlihat dalam tindakan nyata seserorang yaitu tingkah laku yang baik, jujur, bertanggung jawab, menghormati hak orang lain, kerja keras, dan sebagainya. Lebih lanjut dijelaskan bahwa pendidikan karakter adalah segala sesuatu yang dilakukan guru, yang mampu memperngaruhi karakter peserta didik. 
Guru membantu membentuk watak peserta didik. Hal ini mencakup keteladanan bagaimana perilaku guru, cara guru bebicara atau menyampaikan materi, bagaimana guru bertoleransi, dan berbagai hal terkait lainnya. Jadi, Pendidikan karakter adalah sebuah system yang menanamkan nilai-nilai karakter pada peserta didik, yang mengandung komponen pengetahuan, kesadaran individu, tekad, srta adanya kemauan dan tindakan untuk melaksanakan nlai-nilai, baik terhadap Tuhan Yang Maha Esa, diri sendiri, sesama manusia, lingkungan, maupun bangsa, sehingga akan terwujud insane kamil (Suwartini, 2017).

Menyikapi era globalisasi yang bersinergi di dalam arus perubahan informasi dan teknologi yang begitu cepat dibutuhkan nilai-nilai pemersatu bangsa yaitu nilai-nilai Pancasila. Pancasila sebagai alat pemersatu bangsa sebenarnya sudah ada di dalam hati sanubari setiap orang Indonesia, bahkan jauh sebelum kemerdekaan. Hal ini dapat ditunjukkan dengan adanya keharmonisan kehidupan yang dibangun dalam kebersamaan, saling menyayangi, memiliki rasa persaudaraan yang tinggi, dan konsep gotong royong yang tidak pernah dilupakan dan ditinggalkan oleh masyarakat Indonesia. Pancasila menjadi pedoman kehidupan bersama dalam kehidupan bangsa Indonesia. Pancasila memperkokoh kehidupan bangsa dan mempererat persaudaraan antara sesama dalam tatanan kehidupan sosial warga negara.

Nilai-nilai Pancasila harus tetap dibangun dan dibumikan di dalam aktivitas masyarakat Indonesia sehari-hari (Nurgiansah, 2021). Hal ini dilakukan untuk mengantisipasi pihak-pihak yang telah melupakan Pancasila bahkan ada beberapa bagian orang yang belum begitu paham mengenai nilai-nilai Pancasila sebagai ideologi bangsa. Membiasakan dan membumikan Pancasila dalam rangka menjaga karakter kepribadian bangsa Indonesia yang kokoh dan memperkuat persatuan dan kesatuan tanah air Indonesia (Adha, 2020).

\section{Pembahasan}

1. Pancasila sebagai Norma Etik dan Norma Hukum

Pancasila sebagai dasar negara dan ideologi nasional dari negara Indonesia memiliki konsekuensi logis untuk menerima dan menjadikan nilai-nilai Pancasila sebagai acuan pokok bagi pengaturan penyelenggaraan bernegara. Hal ini diupayakan dengan menjabarkan nilai Pancasila tersebut ke dalam UndangUndang Dasar 1945 dan peraturan perundang-undangan yang berlaku. Undang-Undang Dasar 1945 dan peraturan perundang- undangan ini selanjutnya menjadi pedoman penyelenggaraan bernegara (Dewantara \& Nurgiansah, 2021).

Sebagai nilai dasar bernegara, nilai Pancasila diwujudkan menjadi norma hidup bernegara, kemudian Pancasila harus dijabarkan ke dalam norma sebagai praksis dalam kehidupan bernegara. Norma yang tepat sebagai penjabaran atas nilai dasar Pancasila tersebut adalah norma etik dan norma hukum (Nugroho, 2010).

Pancasila dijabarkan sebagai norma etik karena pada dasarnya nilai-nilai dasar Pancasila adalah nilai-nilai moral, dengan demikian Pancasila menjadi semacam etika perilaku para penyelenggara negara dan masyarakat Indonesia agar sejalan dengan nilai normative Pancasila itu sendiri.

Kehidupan dan perkembangan dunia global saat ini terutama bagi Indonesia perlu pelaksanaan secara nyata norma etik untuk kehidupan bernegara sangat penting untuk diterapkan secara berkesinambungan agar terwujud kehidupan bersama yang lebih tenteram dan damai. Tap MPR No. VI/MPR/2001 tentang Etika Kehidupan 
Berbangsa, Bernegara, dan bermasyarakat dinyatakan bahwa etika kehidupan berbangsa, bernegara, dan bermasyarakat merupakan penjabaran nilai-nilai Pancasila sebagai pedoman dalam berpikir, bersikap dan bertingkah laku yang merupakan cerminan dari nilai-nilai keagamaan dan kebudayaan yang sudah mengakar dalam kehidupan masyarakat (Dewantara et al., 2021).

Etika kehidupan berbangsa, bernegara, dan bermasyarakat ini bertujuan untuk: (1) memberikan landasan etik moral bagi seluruh komponen bangsa dalam menjalankan kehidupan kebangsaan dalam berbagai aspek; (2) menentukan pokok-pokok etika kehidupan berbangsa, bernegara, dan bermasyarakat; (3) menjadi kerangka acuan dalam mengevaluasi pelaksanaan nilai-nilai etika dan moral dalam kehidupan berbangsa, bernegara, dan bermasyarakat.

Nilai-nilai Pancasila tidak hanya sebatas panduan dan pelaksanaan secara etik dan moral saja, melainkan kandungan Pancasila harus dapat hidup dalam kepribadian warga negara Indonesia sepanjang masa. Oleh karena itulah, disamping etik dan moral, maka Pancasila harus menjadi sumber utama dalam praksis PKn, tanpa pernah melepaskan Pancasila dalam konteks pembelajaran agar terwujud peserta didik dengan karakter yang kuat dan sangat mencintai bangsanya.

\section{Peran Generasi Muda dalam Mengimplementasikan Nilai-nilai Pancasila}

Bangsa Indonesia telah tumbuh dan berkembang menjadi bangsa yang besar hal ini dapat terlihat dari prestasi-prestasi di tingkat Internasional yang ditorehkan diberbagai bidang. Generasi muda adalah generasi harapan bangsa. Pernyataan ini akan sangat membanggakan bagi masyarakat Indonesia apabila dapat menjadi kenyataan. Akan tetapi, faktanya membuktikan bahwa generasi muda di Indonesia saat ini cenderung mengkhawatirkan perilakunya bagi kelanjutan masa depan bangsa ini (HusinAffan, 2016). Hal ini dapat dilihat dari banyaknya kasus yang terjadi pada generasi muda antara lain kasus narkoba, kejahatan, pergaulan bebas dan lain sebagainya.

Masa depan Bangsa Indonesia sangatlah ditentukan oleh para generasi muda terdahulu ini. Kaum muda indonesia adalah masa depan Bangsa ini. Karena itu, setiap pemuda Indonesia, baik yang masih berstatus pelajar, mahasiswa ataupun yang sudah menyelesaikan pendidikannya merupakan faktor-faktor penting bagi bangsa Indonesia dalam mewujudkan citacita bangsa dan juga mempertahankan kedaulatan bangsa. Dalam upaya mewujudkan cita-cita dan mempertahankan kedaulatan bangsa ini tentu akan menghadapi banyak permasalahan, hambatan, rintangan dan bahkan ancaman yang harus dihadapi. Untuk menyelesaikan masalah-masalah itu penting bagi rakyat Indonesia, terutama kaum pemuda dan mahasiswa untuk membiasakan diri dalam meningkatkan dan memperbaiki produktifitas sebagai bangsa Indonesia (Lestari, 2019).

Semua lapisan masyarakat, tidak hanya generasi muda harus memahami Pancasila (Rahman, 2018). Langkah pertama untuk kembali menguatkan karakter generasi penerus bangsa dengan memberikan pondasi pendidikan, terutama penguatan ideologi bangsa. Hal itu dapat dilakukan dengan memberi pemahaman lagi tentang 4 Pilar Kebangsaan yaitu Pancasila, UUD 45, NKRI, dan Bhinneka Tunggal Ika (Shofa, 2019). Sebagai generasi penerus bangsa yang akan menjadi akar bangsa Indonesia di masa mendatang harus dapat mewujudkan cita-cita dan tujuan nasional dengan memiliki modal dasar yang membuat ia mampu disebut 
sebagai agent of change (agen perubahan) dan agent of social control (agen pengawas sosial).

Peranan pemuda dalam pembangunan bangsa, terutama dalam pembangunan perekonomian, sangat dibutuhkan. Pada hakikatnya, pembangunan yang dilakukan adalah pembangunan insan-insannya, agar bisa menjadi Sumber Daya Manusia (SDM) berkualitas, karena Sumber Daya Alam (SDA) yang melimpah saja tidak cukup jika tidak didukung oleh SDM berkompeten dalam ilmu pengetahuan dan teknologi (Handitya, 2019).

"Apa yang harus kita lakukan sebagai pemuda untuk mewujudkan kemandirian bangsa dalam meningkatkan sumber daya manusia?" Pertama, meningkatkan produktivitas dan kualitas dalam proses industri. Tanpa peningkatan tersebut kita tidak akan mampu bersaing, karena kenyataanya masyarakat kita lebih percaya pada produk luar. Sebuah kalimat "kemandirian" akan terealisasi, jika sebagai penggerak pembangunan pemudanya mampu menciptakan konsep kreatifitas dan daya saing guna memenuhi kebutuhan bangsanya sendiri, baik dalam kebutuhan sandang, pangan maupun papan.

Kedua adalah membiasakan untuk menjadi pencipta sesuatu yang selalu muncul dengan gebrakan-gebrakan kreatifitasnya, sehingga kita sebagai pemuda tidak hanya menjadi penikmat konsumsi. Untuk menghadapi globalisasi dan perubahan yang semakin pesat dibutuhkan peranan pemuda dalam perencanaan menjadi kelompok inovatif, kreatif, kompetitif, mandiri serta mempunyai ketangguhan untuk tetap bertahan pada persaingan dengan dunia luar. Sebenarnya perlu dibangun oleh bangsa Indonesia adalah kualitas SDM, dimana kekuatan terbesar SDM terletak pada generasi muda (Anggraini, 2020).

Ketiga, mewujudkan kemandirian dan kemajuan bangsa perlu didukung oleh kemampuan mengembangkan potensi diri dan konsep yang terarah. Konsep kemandirian itu sendiri bisa diartikan sebagai upaya pemenuhan dan pengerjaan segala sesuatu untuk diri sendiri dengan kekuatan dan kemampuan sendiri. Sebisa mungkin tidak bergantung pada orang lain sesuai dengan semangat yang dicitacitakan oleh Bung Karno: berdiri di atas kaki sendiri (berdikari). Generasi muda hendaknya menyadari bahwa mereka adalah andalan dan harapan bangsa dalam menciptakan perubahan bangsa dari keterbelakangan (Asmaroini, 2016). Maka peran pemuda dalam kondisi ini ialah terlibat langsung dalam memperbaiki keadaan bangsa atau terus belajar menjadi generasi mandiri sehingga bisa membangkitkan bangsa ini dari keterpurukan.

\section{Pancasila dalam Pendidikan}

Salah satu aspek terpenting dalam membangun suatu negara yaitu pendidikan. Untuk membangun pendidikan di Indonesia perlu diterapkan nilai-nilai pancasila didalamnya, sehingga pembangunan dibidang pendidikan dapat membentuk manusia yang berkualitas dan dijiwai oleh nilai-nilai pancasila. Berikut ini adalah beberapa peran dari masing-masing sila dari pancasila dalam ruang lingkup pendidikan:

Ketuhanan yang maha Esa, sila pertama dalam pancasila memiliki peran dalam dunia pendidikan yaitu menjelaskan bahwa Tuhan yang memberikan karunia dan rahmat kepada manusia yang disalurkan menjadi ilmu pengetahuan. Pengetahuan yang telah didapatkan diharapkan dapat menjadi sebuah petunjuk dalam memberi pendidikan kepada seorang anak agar memiliki kepribadian yang bertaqwa kepada Tuhan Yang Maha Esa.

Kemanusian yang adil dan beradab, 
pada sila kedua ini memiliki peran yaitu sebagai acuan guru bagaimana cara yang benar dalam mendidik anak dengan mengutamakan rasa kemanusiaan. Dari segi pendidikan sila ini berperan dalam memperoleh pengetahuan yang berasal dari diri sendiri.

Persatuan Indonesia, Sila persatuan indonesia memiliki makna bahwa kita sebagai pelajar maupun sebagai pengajar diharapkan untuk bersatu. Meskipun di lingkungan masyarakat kita berbeda kebudayaan, agama yang dianut, ras yang dimiliki, suku bangsa dan perbedaan lainnya. Namun, diantara semua perbedaan itu masih ada persamaan diantara masyarakat yaitu kita adalah warga negara Indonesia yang berpegang pada pancasila sebagai pedoman dalam kehidupan. Peran sila ini dalam pendidikan adalah dalam segi pembelajaran di lingkungan sekolah yang harus selalu berpedoman dengan kurikulum yang sama yang ditetapkan oleh negara.

Kerakyatan yang dipimpin oleh hikmat kebijaksanaan dalam permusyawaratan perwakilan, pada sila keempat ini kita diajarkan untuk melakukan demokrasi, teutama dalam melakukan musyawarah agar dapat menerima pendapat orang lain dan menjadi kesepakatan umum. Dalam bidang pendidikan sendiri sila ini dapat menjadi pedoman untuk mengambil keputusan.

Keadilan sosial bagi seluruh rakyat Indonesia, pada sila kelima mengajarkan bahwa seorang pemimpin harus berlaku adil untuk seluruh anggotanya . Di dalam bidang pendidikan sila kelima ini berperan dalam pengajaran contohnya guru tidak boleh membeda-bedakan murid yang satu dengan yang lainnya. Seorang guru haruslah bersikap adil kepada seluruh muridnya.

Pendidikan di Indonesia saat ini cenderung lebih mengedepankan penguasaan aspek keilmuan dan kecerdasan, namun mengabaikan pendidikan karakter (Widiyaningrum, 2019). Aristoteles mendefinisikan karakter yang baik sebagai kehidupan dengan melakukan tindakan-tindakan yang benar sehubungan dengan diri seseorang dan orang lain. Pengetahuan tentang kaidah moral yang didapatkan dalam pendidikan moral atau etika di sekolah-sekolah saat ini semakin ditinggalkan. Sebagian orang mulai tidak memperhatikan lagi bahwa pendidikan tersebut berdampak pada perilaku seseorang.

Dalam menghadapi masalah yang begitu rumit dan komplek seperti di atas dibutuhkan pendidikan karakter yang dibangun melalui pendidikan, yang melibatkan berbagai elemen bangsa terlebih sebagai pemangku kepentingan seperti pendidikan pancasila misalnya. Pendidikan pancasila diharapkan mampu menghadirkan karakter generasi muda yang tidak hanya cerdas namun juga berkarakter. Pendidikan pancasila sangatlah penting bagi para generasi muda Indonesia agar dapat terbentuk karakter yang unggul dan berakhlak mulia. Sehingga mampu bersaing, beretika, bermoral, sopan dan santun dalam bermasyarakat berbangsa dan bernegara. Karena karakter merupakan nilai- nilai perilaku manusia yang berhubungan dengan Tuhan Yang Maha Esa, diri sendiri, sesama manusia, lingkungan, dan kebangsaan, yang terwujud dalam pikiran, sikap, perasaan, perhatian, dan perbuatan berdasarkan norma-norma agama, hukum, tatakrama, budaya dan adat istiadat (Damanhuri, 2016). Sehingga tidak akan ada lagi tindak kriminal seperti kasus korupsi dan lainnya.

Pendidikan pancasila merupakan satu aspek penting untuk membangun karakter generasi bangsa. Hampir semua bangsa menempatkan pembangunan pendidikan sebagai prioritas utama dalam Program Pembangunan Nasional. Sumber daya manusia yang bermutu yang 
merupakan Produk Pendidikan dan merupakan kunci keberhasilan suatu Negara. Oleh sebab itu pendidikan sangat diharuskan sekali karena memberikan peranan yang sangat penting baik itu untuk diri sendiri, orang lain ataupun Negara.

Pendidikan karakter berfungsi mengembangkan potensi dasar agar berhati baik, berpikir baik, dan berprilaku baik; memperkuat dan membangun perilaku bangsa yang multikultur; meningkatkan peradaban bangsa yang kompetitif dalam pergaulan dunia. Keberhasilan penanaman nilai-nilai Budaya dan Karakter Bangsa akan berdampak terhadap penciptaan daya saing dan karakter luhur kehidupan berbangsa dan bernegara pada masa depan. Mempunyai generasi bangsa tangguh, kompetitif, berakhlak mulia, bermoral, bertoleransi, bergotong royong, berjiwa patriotik, berkembang dinamis, berorientasi ilmu pengetahuan dan teknologi yang semuanya dijiwai oleh iman dan takwa kepada Tuhan Yang Maha Esa berdasarkan Pancasila.

\section{KESIMPULAN}

Membumikan dan mengamalkan nilai-nilai Pancasila harus selalu diupayakan dan dilaksanakan untuk membangkitkan semangat Pancasila pada setiap diri warga negara agar lebih memahami, mengerti, dan mampu mengamalkan nilai-nilai Pancasila dalam kehidupan sehari-hari.

Kebanggaan memiliki Pancasila merupakan nilai utama yang harus ditanamkan kepada warga negara. Nilainilai yang terkandung dalam Pancasila bersifat universal sehingga cakupannya sangatlah luas yang meliputi persatuan, kesatuan, perdamaian, gotong royong di dalam masyarakat dengan mengutamakan kehidupan bersama daripada hanya melihat perbedaan yang ada. Membangun sikap mentalitas yang kuat berlandaskan Pancasila dalam kehidupan berbangsa dan bernegara dalam era perubahan yang supercepat seperti sekarang ini sangat menentukan kemajuan dan keberhasilan bangsa Indonesia.

Untuk menaikkan kualitas pendidikan indonesia seperti: banyaknya lembaga pendidikan, fasilitas yang memadai dan merata di indonesia, dan agar dapat meningkatkan sumber daya manusia yang lebih unggul dan berlandaskan pancasila didalamnya. Sistem Pendidikan dalam metode belajar mengajar harus didasarkan dengan nilainilai Pancasila agar teratur dan tearah prosesnya sehingga mewujudkan tujuan Pendidikan yang sebenarnya. Rendahnya kualitas Pendidikan Indonesia yaitu efektivitas yang masih rendah, efesiensi pengajaran Indonesia, dan standarisasi Pendidikan Indonesia yang sering disalah artikan. Jika Pendidikan di Indonesia berkualitas maka sangat bermanfaat bagi sumber daya manusia.

Suatu cara yang sangat tepat untuk memberikan pondasi moral anak bangsa adalah dengan pendidikan karakter yang berdasar Pancasila. Pada intinya pendidikan karakter Pancasila ini bertujuan membentuk bangsa yang tangguh, kompetitif, berakhlah mulia, bermoral, bertoleransi, bergotong royong, berjiwa patriotik, berkembang dinamis, berorientasi ilmu pengetahuan dan teknologi yang semuanya dijiwai oleh iman dan takwa kepada Tuhan Yang Maha Esa berdasarkan Pancasila.

\section{DAFTAR PUSTAKA}

Adha, M. M., \& Susanto, E. (2020). Kekuatan Nilai-nilai Pancasila dalam Membangun Kepribadian Masyarakat Indonesia. Al-Adabiya: Jurnal Kebudayaan dan Keagamaan, 15(01), 121-138. 
Anggraini, D., Fathari, F., Anggara, J. W., \& Al Amin, M. D. A. (2020). Pengamalan nilai- nilai Pancasila bagi generasi milenial. Jurnal Inovasi Ilmu Sosial dan Politik (JISoP), 2(1), 1118.

Asmaroini, A. P. (2016). Implementasi Nilai-Nilai Pancasila Bagi Siswa Di Era Globalisasi. Citizenship Jurnal Pancasila dan Kewarganegaraan, 4(2), 440-450.

Damanhuri, D., Bahrudin, F. A., Legiani, W. H., \& Rahman, I. N. (2016). Implementasi Nilai- Nilai Pancasila Sebagai Upaya Pembangunan Karakter Bangsa. Untirta Civic Education Journal, 1(2).

Dewantara, J. A., \& Nurgiansah, T. H. (2021). Building Tolerance Attitudes Of PPKN Students Through Multicultural Education Courses. Jurnal Etika Demokrasi, 6(1), 103-115.

Dewantara, J. A., Nurgiansah, T. H., \& Rachman, F. (2021). Mengatasi Pelanggaran Hak Asasi Manusia dengan Model Sekolah Ramah HAM (SR-HAM). Edukatif: Jurnal Ilmu Pendidikan, 3(2), 261-269.

Handitya, B. (2019). Menyemai Nilai Pancasila Pada Generasi Muda Cendekia. ADIL Indonesia Journal, 1(2).

HusinAffan, M., \& Maksum, H. (2016). Membangun Kembali Sikap Nasionalisme Bangsa Indonesia Dalam Menangkal Budaya Asing Di Era Globalisasi M. Jurnal Pesona Dasar, 3(4), 65-72.

Kariyadi, D. (2017). Membangun Kepemimpinan Berbasis Nilai-Nilai Pancasila Dalam Perspektif Masyarakat Multikultural. Citizenship Jurnal Pancasila Dan Kewarganegaraan, 5(2), 86-96.

Lestari, E. Y. (2019). Menumbuhkan kesadaran nasionalisme generasi muda di era globalisasi melalui penerapan nilai-nilai Pancasila. ADIL Indonesia Journal, 1(1).

Nugroho, I. (2010). NILAI-NILAI PANCASILA SEBAGAI FALSAFAH PANDANGAN HIDUP BANGSA UNTUK PENINGKATAN KUALITAS SUMBER DAYA MANUSIA DAN PEMBANGUNAN LINGKUNGAN HIDUP. Jurnal Konstitusi, 3(2), 107-128.

Nurgiansah, T. H. (2020). Fenomena Prostitusi Online Di Kota Yogyakarta Dalam Persfektif Nilai Kemanusiaan Yang Adil Dan Beradab. Jurnal Kewarganegaraan, 17(1), 27-34. https://doi.org/10.24114/jk.v17i1.14208

Nurgiansah, T. H. (2021). Pendidikan Pancasila. In Solok: CV Mitra Cendekia Media.

Putri, A. L., Charista, F. D. F., Lestari, S., \& Trisiana, A. (2020). Implementasi Pancasila Dalam Pembangunan Dibidang Pendidikan. TERAMPIL: Jurnal Pendidikan dan Pembelajaran Dasar, 7(1), 13-22.

Rahman, A. (2018). Nilai Pancasila Kondisi Dan Implementasinya Dalam Masyarakat Global. Syntax Literate; Jurnal Ilmiah Indonesia, 3(1), 34-48.

Shofa, A. M. I. A., Kodir, A., Alfaqi, M. Z., \& Subekti, A. (2019). Wanua Nusantara: Praktik Pembumian Nilai-Nilai Pancasila di Kalangan Generasi Muda. Jurnal Praksis dan Dedikasi Sosial (JPDS), 1-5.

Suwartini, S. (2018). Pendidikan karakter dan pembangunan sumber daya manusia keberlanjutan. Trihayu: Jurnal Pendidikan Ke-SD-an, 4(1).

Widiyaningrum, W. Y. (2019). Menumbuhkan Nilai Kesadaran Pancasila di Kalangan Generasi Muda: Kajian Teoritis. JISIPOL| Jurnal Ilmu Sosial dan Ilmu Politik, 3(3), 69- 78. 